\title{
Clinical Decision-Making in Blood Pressure Management of Patients with Diabetes Mellitus: An Oklahoma Physicians Resource/Research Network (OKPRN) Study
}

\author{
Adam Cotton, MSIV, Cheryl B. Aspy, PhD, James Mold, MD, MPH, and \\ Howard Stein, PhD
}

Background: Outcomes can be improved when the blood pressure (BP) is kept below 130/80 in patients with diabetes mellitus. However, physicians and patients achieve this target less than $50 \%$ of the time. The purpose of this study was to determine the reasons for this apparent quality deficit from the perspective of a small random sample of family physicians.

Methods: Nine family physicians completed interviews about encounters with diabetic patients with $\mathrm{BP} \geq \mathbf{1 3 0 / 8 0}$ for whom no change in management was recorded. Four investigators analyzed the transcribed interviews to identify and categorize reasons for failure to intervene.

Results: Ninety-eight (62\%) of 159 patients had $\mathrm{BP} \geq 130 / 80$ at the index visit. No change in management was recorded in 73 (74\%). Physicians gave 175 reasons for nonintervention in 3 broad categories, physician-related, patient-related, and information/measurement-related reasons, and 10 subcategories. In most cases they gave more than one reason (mean 2.4) per case. The most frequent subcategories were limited treatment options $(47 / 73 ; 64 \%)$, inadequate information on which to intervene $(43 / 73 ; 59 \%)$, and patient nonadherence $(27 / 73 ; 37 \%)$. Competing demands were mentioned in 10 cases (13.7\%). Physicians differed with regard to the kinds of reasons given.

Conclusions: Physicians have a variety of clinical reasons for not responding to elevated BP in diabetic patients. Some might be addressed with better technology (eg, more reliable BP measurements) or health care system reforms (eg, less expensive medications). Others (eg, patient nonadherence) are more challenging. Methods for measuring quality must be robust enough to account for legitimate clinical reasons for not achieving BP targets. Physician-based interventions will need to take into account different physician personalities and practice styles. (J Am Board Fam Med 2006;19:232-9.)

Seventy percent of patients with diabetes also have hypertension [defined as a blood pressure (BP) $>140 / 90],{ }^{1,2}$ which increases their risk for development of both macrovascular and microvascular dis-

Submitted 12 July 2005; revised 21 September 2005; accepted 30 September 2005.

From the University of Oklahoma College of Medicine, University of Oklahoma Health Sciences Center, Department of Family and Preventive Medicine, Oklahoma City, OK.

Funding: This project was funded by the Department of Family and Preventive Medicine, University of Oklahoma Health Sciences Center as a project of the Family Medicine Summer Research Experience.

Conflict of interest: none declared.

This study was presented at a Research Conference, Department of Family and Community Medicine, Baylor College of Medicine, Houston, TX, March 2005.

Corresponding author: Cheryl B. Aspy, $\mathrm{PhD}$, Department of Family and Preventive Medicine, University of Oklahoma College of Medicine, University of Oklahoma Health Sciences Center, $900 \mathrm{NE}$ 10th Street, Oklahoma City, OK 73104 (E-mail: Cheryl-apsy@ouhsc.edu). ease. ${ }^{3-5} \mathrm{BP}$ reduction in patients with diabetes significantly reduces the occurrence of cardiovascular events and death, ${ }^{1,6-13}$ and intensive BP control can slow the progression of diabetic nephropathy and retinopathy. ${ }^{12}$

Widely accepted guidelines recommend that BPs be kept below 130/80 $\mathrm{mm} \mathrm{Hg}^{10,11,14-16}$ in patients with diabetes, and treatment to this target has been shown to be cost effective. ${ }^{16}$ However, studies have shown that clinicians often fail to achieve this target, ${ }^{6,7,15,17-20}$ and an estimated 50\% to $75 \%$ of diabetic patients in the United States have mean BPs $>130 / 80$. $^{7}$

Oliveria et al found that the most frequent physician-reported reasons for nonintervention were that a satisfactory response had occurred (35\%), continued monitoring was indicated before making additional medication changes (30\%), there were competing priorities or agendas (29\%), and some 
patients were noncompliant with recommendations $(18 \%) .{ }^{20}$ Berlowitz et al found that physicians were less successful in managing hypertension in diabetic patients and that this was partly because they were less aggressive in patients with diabetes than in nondiabetic patients. ${ }^{7}$ Phillips suggested the term "clinical inertia" to describe physicians' behavior with regard to BP control. ${ }^{21-25}$

The purpose of this qualitative study was to more carefully explore the reasons that family physicians choose not to intervene with some diabetic patients with elevated BP. In contrast to prior studies that relied on paper-and-pencil surveys, ${ }^{20,26}$ we directly interviewed physicians about their decision-making process within 2 weeks of an index encounter with the patient's medical record available for review.

\section{Research Design and Methods}

This study was approved by the University of Oklahoma Health Sciences Center Institutional Review Board and was conducted in the Oklahoma Physicians Resource/Research Network (OKPRN), a primary care practice-based research network with 160 physician members. Twelve practicing physicians were selected, using a random numbers table, and invited to participate. Nine of the twelve agreed to participate and gave informed consent. Of those who declined, one did so because of an office move, one was on vacation, and the third was ill. All participants were practicing physicians who had completed a residency in Family Medicine and were board certified.

The medical records of all patients with a diagnosis of diabetes mellitus seen by each of the participating physicians for any reason during the prior 2-week period were held by the office nurse so that one of the authors (AC) could determine whether the patient's recorded $\mathrm{BP}$ at that visit was $>130 / 80$. If so, the chart was examined for physician-recommended interventions that might result in lower BP (eg, diet, exercise, medications). If no intervention was documented, basic sociodemographic information was recorded, and the patient was added to the physician's interview list. No interview occurred more than 2 weeks after the index visit. Structured interviews were used to elicit the physicians' rationale(s) for not intervening to lower BP to the recommended target. Patient medical records were available during the interviews although the physicians were not required to review them. Physicians were paid \$75 per interview session.

The interviewer, a 2nd year medical student, followed a script that included both open-ended questions (eg, what factors influenced your decision not to intervene in this case?) and closed questions (eg, do you agree with the current guidelines that suggest keeping BP levels below 130/80 in diabetic patients?). Additional questions could be added to clarify responses at interviewer discretion. Informal training and feedback were provided to the interviewer by the other research team members, a family physician faculty member, a nonphysician educator and researcher, and a psychoanalytic anthropologist, who have extensive experience in conducting interviews. All interviews were audiorecorded and transcribed. All 4 members of the research team reviewed the transcripts, first by encounter, and then by physician, to identify and categorize reasons for nonintervention. Final reasons, categories, and subcategories were determined by consensus.

The data were entered into QSR N-Vivo, coded and analyzed. Descriptive statistics were computed for patient gender, age, BP at the time of visit, insurance coverage, and number of BP medications taken using SimStat v.2.1 (Provalis Research).

\section{Results}

During this 8 -week study, the 9 participating physicians saw a total of 159 adult diabetic patients. Ninety-eight patients (62\%) had BPs $>130 / 80$ at the index visit. Interventions were documented in $25(26 \%)$ of these, leaving 73 that met study inclusion criteria. Three participating physicians were in private community practices, 2 practiced at an academic medical center, 2 worked in community hospital-based residency programs, one was in an Indian tribal clinic, and one practiced in a federally funded community health center. Seven had been in practice for more than 10 years. A majority of eligible patients, $(42 ; 58 \%)$ were seen in the private practices, all located in medium-sized towns (population, 20,000 to 50,000; also, see Table 1).

The mean age (SD) of study patients was 62.8 (14.0), with a range of 33 to 88 . Sixty percent were female; $57 \%$ were insured by Medicare, $25 \%$ had private insurance, $7 \%$ Medicaid, Indian Health, or military insurance, and $11 \%$ were uninsured. Their 
Table 1. Characteristics of Participating Physicians

\begin{tabular}{|c|c|c|c|c|c|c|c|c|c|c|}
\hline Characteristic & Physician & A & B & $\mathrm{C}$ & $\mathrm{D}$ & $\mathrm{E}$ & $\mathrm{F}$ & G & $\mathrm{H}$ & I \\
\hline Physician gender & Males $=78 \%$ & M & $\mathrm{F}$ & $\mathrm{F}$ & M & M & M & M & M & M \\
\hline Type of practice: academic vs. private & & $\mathrm{P}$ & $\mathrm{P}$ & A & A & $\mathrm{P}$ & A & $\mathrm{P}$ & $\mathrm{P}$ & A \\
\hline Years in practice* & & 2 & 1 & 3 & 3 & 3 & 3 & 3 & 3 & 3 \\
\hline Location of practice $\dagger$ & & $\mathrm{U}$ & $\mathrm{R}$ & $\mathrm{U}$ & $\mathrm{R}$ & $\mathrm{R}$ & $\mathrm{U}$ & $\mathrm{R}$ & $\mathrm{R}$ & $\mathrm{U}$ \\
\hline No. of patients not meeting guidelines & & 7 & 2 & 5 & 10 & 11 & 6 & 11 & 21 & 2 \\
\hline $\begin{array}{l}\text { Average no. of reasons given per patient } \\
\quad(\text { group mean }=2.3)\end{array}$ & & 3.4 & 2.5 & 3.0 & 2.0 & 1.9 & 2.5 & 2.5 & 1.9 & 4.0 \\
\hline Percentage of physician-related reasons & & 8.3 & 40 & 8 & 40 & 71 & 0 & 16 & 28 & 0 \\
\hline Percentage of patient-related reasons & & 83.3 & 40 & 54 & 35 & 19 & 100 & 47 & 33 & 75 \\
\hline Percentage of information-related reasons & & 8.3 & 5 & 13 & 20 & 21 & 5 & 38 & 39 & 0 \\
\hline
\end{tabular}

${ }^{*} 1=<5$ years; $2=5-10$ years; $3=>10$ years.

$\dagger \mathrm{R}=$ rural; $\mathrm{U}=$ urban.

mean (SD) systolic and diastolic BPs at the index visit were 145.7 (11.0) and 80.7 (10.2) $\mathrm{mm} \mathrm{Hg}$.

All physicians were familiar with recommended BP targets and all but one agreed with them. Physicians cited 175 reasons for not recommending additional measures to reduce the elevated BPs in the 73 patients (2.4 per patient); however, 18 (25\%) patients had only 1 reason cited, and of these, $50 \%$ gave the reason for not making a change as "lack of a consistent trend." The reasons cited per patient ranged from 1 to 6 with 34\% having 2 reasons, $20.5 \%$ had 3 reasons, and $20.5 \%$ had 4 or more reasons. The reasons given could be divided into 3 categories, physician-related, patient-related, and information/measurement-related reasons, and 10 subcategories (Table 2).

The most common physician-related reason for nonintervention was satisfaction with the patient's progress toward $\mathrm{BP}$ control or the decision to wait for the full effect of current interventions. For example, "... she is just in the process of retiring from the college here in town where she is a librarian, and I am hoping after she does that, that she's going to watch her diet more closely and exercise more ..." and "he has been losing weight and his pressure's been trimming down the last 3 visits from $150 / 70$ to $140 / 90$ to $138 / 80$..., so I'm hoping to get there with his weight loss." This reason was mentioned in $27.4 \%$ of all the interviews conducted.

Another common physician-related reason, mentioned in $13.7 \%$ of the interviews, was "competing demands" (ie, other problems were deemed more important at that visit). An example was, "on her last visit she was found to be in atrial fibrillation which is a brand new diagnosis for her ..." and "It's just that we had more pressing issues ... she actually developed some systemic changes in the feet that looked gangrenous."

In $12.3 \%$ of cases, the physician was "co-managing" the patient with another physician (eg, a cardiologist or nephrologist) who was also managing the patient's BP medications. This can be characterized by the following statement: "She (patient) is co-managed with a cardiologist, and to tell you quite frankly, I'm not always sure what my role is ..."

Only one physician said that he did not agree with the 130/80 target. His comments included, "Because I consider 140/90 normal" and "I wouldn't treat anybody with BPs of 136/84." Another physician seemed less than completely convinced, stating, "I don't think she has a blood pressure problem right now" even though the BP was $>130 / 80$.

The patient-related category included 4 subcategories. The most frequently occurring were limited treatment options (64\%) and physician-perceived patient nonadherence (37\%). Limited treatment options included the high cost of medications/inadequate insurance (37\%), adverse side effects of medications (16.4\%), and comorbidities (11\%). Representative statements included: "Medication costs were the main factor that I took into account" and "She is on a fixed income and there is no pharmacy coverage for her...." (cost), "I have her on an ARB and a beta blocker, and she was complaining of fatigue and we just actually had a decrease in her Diovan dose" (side effects); and "He's got a big problem with ... alcoholism and cirrhosis of the liver" (comorbidity). 
Table 2. Reasons Given for Not Achieving BP $<130 / 80$ (no.of cases $=73$ )

\begin{tabular}{|c|c|c|}
\hline Category Descriptor & Frequency & $\begin{array}{l}\text { Percentage } \\
\text { of Cases }\end{array}$ \\
\hline \multicolumn{3}{|l|}{ Physician-related $(\mathrm{N}=45)$} \\
\hline Satisfied with results/progress & 20 & 27.4 \\
\hline Competing demands & 10 & 13.7 \\
\hline Co-management & 9 & 12.3 \\
\hline $\begin{array}{l}\text { Disagreement with } \mathrm{ADA}^{*} \\
\text { guidelines }\end{array}$ & 6 & 8.2 \\
\hline \multicolumn{3}{|l|}{ Patient-related $(\mathrm{N}=82)$} \\
\hline Limited treatment options & 47 & 64 \\
\hline $\begin{array}{l}\text { Low income/medication cost/ } \\
\text { inadequate insurance }\end{array}$ & 27 & 37 \\
\hline Adverse effects of medications & 12 & 16.4 \\
\hline $\begin{array}{l}\text { Comorbidities limiting } \\
\text { treatment options }\end{array}$ & 8 & 11.0 \\
\hline Patient adherence issues & 27 & 37 \\
\hline General nonadherence & 14 & 19.2 \\
\hline Denial & 3 & 4.1 \\
\hline Alcoholism & 3 & 4.1 \\
\hline Cultural issues & 2 & 2.7 \\
\hline Depression & 2 & 2.7 \\
\hline Dementia & 2 & 2.7 \\
\hline $\begin{array}{l}\text { Language/communication } \\
\text { barriers }\end{array}$ & 1 & 1.4 \\
\hline Competing agendas & 5 & 6.9 \\
\hline Unfavorable risk to benefit ratio & 3 & 4.1 \\
\hline \multicolumn{3}{|l|}{$\begin{array}{l}\text { Information/measurement-related } \\
\qquad(N=48)\end{array}$} \\
\hline $\begin{array}{l}\text { Inadequate data or data } \\
\text { variability }\end{array}$ & 43 & 58.9 \\
\hline Lack of a consistent trend & 26 & 35.6 \\
\hline Unusual circumstances & 7 & 9.6 \\
\hline $\begin{array}{l}\text { Discrepancy between home } \\
\text { and office }\end{array}$ & 5 & 6.9 \\
\hline Lack of information & 3 & 4.1 \\
\hline Unable to get accurate BP & 2 & 2.7 \\
\hline Intervention not recorded & 5 & 6.9 \\
\hline
\end{tabular}

* ADA, American Diabetic Association; BP, blood pressure.

Patient nonadherence could be subdivided into general nonadherence $(19.2 \%)$, denial $(4.1 \%)$, alcoholism (4.1\%), cultural issues $(2.7 \%)$, depression and dementia (each $2.7 \%$ ), and language/communication barriers (1.4\%). Examples were: "Basically, compliance is the main factor that needs to be taken into account. .. ," "... but if he does start drinking, then he can get real noncompliant," and "... the grief and depression were complicating what was going on as well..."

We distinguished competing patient agendas, mentioned in $6.9 \%$ of cases, from competing demands. Examples of the former were, "She was just a drop-in that day because she had some swelling in her arm. .." and "She insists she has no symptoms though, and what she came to ask me this day was to decrease her medication rather than increase it."

In $4.1 \%$ of interviews, physicians said that the patient was on multiple medications and the riskto-benefit ratio of adding another was too high to warrant a change. An example related to a 90 -yearold man was: "I don't really think that lowering his $\mathrm{BP}$ to ADA standards is going to substantially improve either his length or quality of life at this point."

In the information and measurement category, the most common subcategory cited was "lack of a consistent trend." In over a third (35.6\%) of the interviews, the elevated $\mathrm{BP}$ was inconsistent with prior documented lower readings. An example is, "She's another one of those who will vary, . . . back a couple of office visits, she was running 120 over 76." In $9.6 \%$ of cases, the physician distrusted the BP measurement on that day because of some unusual circumstances (eg, the patient forgot to take their medications or was in pain). Another 6.9\% reported that their pressures taken at home were below 130/80, and the physician used this as a reason for not intervening despite $\mathrm{BP}$ elevation in the office.

Physicians approached decisions about intervention differently. Most viewed BP control as a complex balancing act involving cost, quality of life, and future benefits, the latter being most difficult to estimate for a given individual. However, different clusters of reasons for nonintervention were given by different physicians. For example, some physicians tended to focus on lifestyle changes, allowing plenty of time for patients to modify their diets, exercise programs, and stress levels; some were more concerned about the costs of medications, going out of their way to try to minimize them; others co-managed a number of patients with cardiologists and nephrologists with confusion at times about roles; still others distrusted office BP readings, particularly when they varied from visit to visit or didn't correlate with reported home readings. These differences may have reflected differences in personality, practice style, practice settings, and patient populations (also see Table 1).

\section{Discussion}

Much has been written about why physicians don't always follow clinical guidelines in general. ${ }^{27} \mathrm{~A}$ 
systematic review of the English language literature published between 1966 and 1998 included 120 different surveys investigating 293 potential barriers to guideline adherence. ${ }^{28}$ These reviewers categorized the reasons as follows: lack of awareness, familiarity, or agreement with the guidelines; low self-efficacy or high inertia; low outcome expectations; and external barriers. They also suggested that interventions addressed at single barriers are less likely to be successful than those that address multiple, often less obvious barriers, and that the spectrum and distribution of barriers are likely to vary across guidelines, clinicians, and settings.

In a similar study, general internists were asked to record their reasons for nonadherence to diabetes care guidelines in an open-ended format. Results suggested that physicians followed some guidelines more often than others and common reasons for nonadherence included oversight (physician forgot), patient nonadherence, and "systems issues" (failure of consultants to send reports, patient can't afford medication, tested but not yet documented, etc). ${ }^{29}$ Similar reasons have been documented for physicians' failure to consistently lower A1c levels to below $8 \% .^{30}$ In primary care settings, physicians also choose not to follow guidelines for a variety of practical and clinical reasons. ${ }^{31}$

We believe that the interviews conducted in our study yielded additional insights into the complex decision-making process used by primary care physicians to determine whether to intervene when BPs are elevated in diabetic patients. Some reasons were the same as those reported by others, including satisfaction with progress, competing agendas, and patient nonadherence, ${ }^{20,26}$ whereas others have not previously been emphasized. In addition, we documented that clinicians often have more than one reason in each case for not intervening.

There was some evidence supporting "clinical inertia." 32,33 Follow-up appointments were often set farther in the future than needed to see the effect of an intervention, and physicians were willing to accept slow progress over prolonged periods of time. Ferrari and colleagues found that physicians tended to base their interventions as much on how far the BP had been reduced from baseline as on specific BP targets, ${ }^{34}$ and that seemed to hold true for our physicians. Given the lack of information on the relative impact of incremental reductions of $\mathrm{BP}$ in higher versus lower ranges, this approach may or may not be reasonable.
In more than a third of patient encounters, physician or patient-perceived cost of medications was one of the reasons given for suboptimal BP control. This rate may be higher than in the general primary care population, because several of the participating physicians worked in practices with larger than average numbers of low-income and underinsured patients (eg, academic and community health centers). Patient nonadherence could not, of course, be verified, but physicians generally listed specific plausible reasons or examples (eg, alcoholism, dementia, etc). In addition, our study reflects more stringent guidelines $(<130 / 80$; deviance at a single office visit) than previous studies, so our results may reflect more significant barriers to achieving control at this level.

Jaen, Barnes, Stange, Zyzanski and others have documented that competing demands are common in primary care practice, ${ }^{35-38}$ and so we were a little surprised that this reason was mentioned as a factor in only $13.7 \%$ of the cases. It is possible that physicians were reluctant to mention it, believing that it was less acceptable than other explanations, or it may be related to the physician and patient populations studied. On the other hand, confusion related to co-management was much more frequent than previously reported.

Failure to address elevated BPs was not usually the result of unfamiliarity or disagreement with the guidelines, and although we were unable to fully judge the clinical legitimacy of the reasons given for nonintervention, many had substantial face validity. For example, limited treatment options were noted in $64 \%$ of cases. For these patients, either the cost of the medicine often combined with lack of insurance, adverse effects of prior medications, or comorbidities limited the physician's ability to provide the care he or she would have liked to have provided.

In almost $60 \%$ of cases, the BP measurement itself was felt to be suspect for a variety of reasons including inconsistency with previous office readings or home monitoring. Because this reason had not been reported by others, it was somewhat unexpected, although it has substantial face validity for practicing physicians. The concern physicians' expressed about changing medication based on a single BP measure was not considered in the Phillips et al tripartite description of clinical inertia. ${ }^{21}$

The strengths of this study are its qualitative design, which made it possible to get a more com- 
plete view of physician decision making, randomized selection of physicians, diversity of the settings in which participating physicians practiced, and that we were able to interview physicians within 2 weeks of the encounters. Weaknesses include the relatively small numbers of physicians and patients involved and the fact that the physician participants were all members of a practice-based research network. The interviews were also relatively brief and highly structured making it difficult to achieve substantial depth of analyses.

As with any qualitative study, bias could also have been introduced because of selection bias, during the interviews, or during data analysis. The study included a relatively small number of physicians all practicing in Oklahoma. Nearly half practiced in teaching settings. Participating physicians did not seem to be reluctant to talk with the interviewer, a 2nd year medical student. All believed themselves able to be open and honest in their assessment of their performance, and all were committed to producing accurate, reliable data for the study. However, it is still possible that they avoided negative self-assessments. The use of 4 independent coders and requirement for consensus probably minimized analysis bias, but given that all 4 worked in primary care settings, their judgments may have been influenced by the belief that physicians are often criticized unfairly for not following guidelines.

Physicians can do a much better job of controlling BP in diabetic patients. ${ }^{34}$ Future research should evaluate newer models of chronic disease management (eg, chronic care model) as a way to increase adherence to agreed upon standards. A greater emphasis on BP control at a health systems level (eg, through pay-for-performance) could certainly have some influence over physician and patient behavior. Closer linkages between primary care practices and community resources might reduce some financial barriers and improve adherence to lifestyle modifications. More support for patient self-management could transfer more of the responsibility to patients and assure that a greater percentage monitor their BPs at home. Clinical information systems could be used to conduct periodic audits with feedback and reminders, and electronic decision support systems could keep the recommendations in front of the physician and patient. Practice design changes such as greater involvement of physician extenders and cluster and group visits for diabetic patients could make care more predictable and systematic, and greater use of newer automated office and home BP measurement approaches should reduce variability and increase physician confidence in the results. ${ }^{39}$ All these approaches will require additional resources. As a society we need to insure that cost isn't such a significant factor in determining the quality of health care available. Primary care office visits should be reimbursed well enough to allow time for all health issues to be addressed.

Evidenced-based recommendations for BP control in diabetics serve as a valuable guide but do not fit all patients or all clinical scenarios. ${ }^{40} \mathrm{We}$ discovered that, in most cases, the decision not to intervene had a great deal to do with that particular patient's unique situation at a particular point in time. If converted into quality indicators, primary care physicians might be encouraged to do the wrong thing for some of their patients. ${ }^{41,42}$ Alternatively, physicians might become more selective in their acceptance of new patients, and complex and challenging patients may have even greater difficulty finding physicians. ${ }^{42-44}$ Having said this, controlling BP in appropriate patients with diabetes mellitus is one of the most effective ways to prevent premature death and disability. We just need to make sure that our quality assessment methods are robust enough to account for legitimate reasons for deviations from standards.

Future research should therefore focus both on understanding the perspectives of both physicians and patients in the decision-making process and on ways to more accurately access quality of care as it relates to patient-oriented outcomes. In both regards, a great deal of qualitative research remains to be done.

We acknowledge the assistance of our staff in preparing the manuscript and to the physicians and their staff who took time out of their busy schedules to participate in our study.

\section{References}

1. Contreras F, Rivera M, Vasquez J, De la Parte MA, Velasco M. Diabetes and hypertension physiopathology and therapeutics. J Hum Hypertens 2000; 14(Suppl 1):S26-31.

2. Geiss LS, Rolka DB, Engelgau MM. Elevated blood pressure among U.S. adults with diabetes, 19881994. Am J Prev Med Jan 2002;22:42-8.

3. UK Prospective Diabetes Study Group. Efficacy of atenolol and captopril in reducing risk of macrovas- 
cular and microvascular complications in type $2 \mathrm{di}-$ abetes: UKPDS 39.BMJ 1998;317:713-20.

4. Arauz-Pacheco C, Parrott MA, Raskin P, American Diabetes Association. Hypertension management in adults with diabetes. Diabetes Care 2004;27 Suppl 1:S65-7.

5. Bakris GL, Williams M, Dworkin L, et al. Preserving renal function in adults with hypertension and diabetes: a consensus approach. National Kidney Foundation Hypertension and Diabetes Executive Committees Working Group. Am J Kidney Dis 2000;36:646-61.

6. Bakris GL. The importance of blood pressure control in the patient with diabetes. Am J Med 2004;116 Suppl 5A:30S-8S.

7. Berlowitz DR, Ash AS, Hickey EC, Glickman M, Friedman R, Kader B. Hypertension management in patients with diabetes: the need for more aggressive therapy. Diabetes Care 2003;26:355-9.

8. Brenner BM, Cooper ME, de Zeeuw D, et al. Effects of losartan on renal and cardiovascular outcomes in patients with type 2 diabetes and nephropathy. N Engl J Med 2001;345:861-9.

9. Dagenais GR, Yusuf S, Bourassa MG, et al. Effects of ramipril on coronary events in high-risk persons: results of the Heart Outcomes Prevention Evaluation Study. Circulation 2001;104:522-6.

10. Gerstein HC. Reduction of cardiovascular events and microvascular complications in diabetes with ACE inhibitor treatment: HOPE and MICROHOPE. Diabetes Metab Res Rev 2002;18(Suppl 3): S82-5.

11. Kaplan NM. Management of hypertension in patients with type 2 diabetes mellitus: guidelines based on current evidence. Ann Intern Med 2001;135: 1079-83.

12. Schrier RW, Estacio RO, Esler A, Mehler P. Effects of aggressive blood pressure control in normotensive type 2 diabetic patients on albuminuria, retinopathy and strokes. Kidney Int 2002;61:1086-97.

13. Snow V, Weiss KB, Mottur-Pilson C. Clinical Efficacy Assessment Subcommittee of the American College of Physicians. The evidence base for tight blood pressure control in the management of type 2 diabetes mellitus. Ann Intern Med 2003;138:587-92.

14. American Diabetes Association. Standards of medical care for patients with diabetes mellitus. Diabetes Care 2003;26(Suppl 1):S33-50. Erratum in: Diabetes Care 2003;26:972.

15. Chobanian AV, Bakris GL, Black HR, et al. Seventh report of the Joint National Committee on Prevention, Detection, Evaluation, and Treatment of High Blood Pressure. Hypertension 2003;42:1206-52.

16. Jonsson B, Hansson L, Stalhammar NO. Health economics in the Hypertension Optimal Treatment (HOT) study: costs and costeffectiveness of intensive blood pressure lowering and low-dose aspirin in pa- tients with hypertension. J Intern Med 2003;253: $472-80$.

17. Coon P, Zulkowski K. Adherence to American Diabetes Association standards of care by rural health care providers. Diabetes Care 2002;25:2224-9.

18. Goetzel RZ, Hawkins K, Ozminkowski RJ, Wang S. The health and productivity cost burden of the "top 10 " physical and mental health conditions affecting six large U.S. employers in 1999. J Occup Environ Med 2003;45:5-14.

19. Miller CD, Phillips LS, Tate MK, et al. Meeting American Diabetes Association guidelines in endocrinologist practice. Diabetes Care 2000;23:444-8.

20. Oliveria SA, Lapuerta P, McCarthy BD, L'Italien GJ, Berlowitz DR, Asch SM. Physician-related barriers to the effective management of uncontrolled hypertension. Arch Intern Med. 2002;162:413-20.

21. Phillips LS, Branch WT, Cook CB, et al. Clinical inertia. Ann Intern Med 2001;135:825-34.

22. O'Connor PJ. Overcome clinical inertia to control systolic blood pressure. Arch Intern Med 2003;163: $2677-8$

23. Reinharth D. Clinical inertia. Ann Intern Med 2002; 137:547-8; author reply 547-8.

24. Steinberg M. Clinical inertia. Ann Intern Med 2002; 137:547-8; author reply 547-8.

25. Wofford JL. Clinical inertia. Ann Intern Med 2002; 137:547-8; author reply 547-8.

26. National Heart, Lung, and Blood Institute. Diagnosis and management of hypertension-1987: a nationwide survey of physicians' knowledge, attitudes, and reported behavior. Bethesda: National Institutes of Health, U.S. Department of Health and Human Services; 1989. NIH Publications 89-2968.

27. Hofer TP, K. J. Zemencuk, Hayward RA. When there is too much to do: how practicing physicians prioritize among recommended interventions. J Gen Intern Med. 2004;19:646-53.

28. Cabana MD, Rand CS, Powe NR, et al. Why don't physicians follow clinical practice guidelines? JAMA 1999;282:1458-65.

29. Mottur-Pilson C, Snow V, Bartlett K. Physician explanations for failing to comply with "best practice". Eff Clin Pract 2001;4:207-13.

30. Parnes BL, Main DS, Dickinson LM, et al. Clinical decisions regarding $\mathrm{HbAlc}$ results in primary care: a report from CaReNet and HPRN. Diabetes Care 2004;27:13-6.

31. James PA, Cowan TM, Graham RP. Patient-centered clinical decisions and their impact on physician adherence to clinical guidelines. J Fam Pract 1998; 46:311-8.

32. Andrade SE, Gurwitz JH, Field TS, et al. Hypertension management: the care gap between clinical guidelines and clinical practice. Am J Managed Care 2004;Jul 10(7 Pt 2):481-6.

33. Cook CB, Ziemer DC, El-Kebbi IM, et al. Diabetes 
in urban African-Americans. XVI. Overcoming clinical inertia improves glycemic control in patients with type 2 diabetes. Diabetes Care 1999;22:1494500.

34. Ferrari P, Hess L, Pechere-Bertschi A, Muggli F, Burnier M. Reasons for not intensifying antihypertensive treatment (RIAT): a primary care antihypertensive intervention study. J Hypertens 2004;22: 1221-9.

35. Jaen CR, Stange KC, Tumiel LM, Nutting P. Missed opportunities for prevention: smoking cessation counseling and the competing demands of practice. J Fam Pract 1997;45:348-54.

36. Barnes CS, Ziemer DC, Miller CD, et al. Little time for diabetes management in the primary care setting. Diabetes Educator 2004;30:126-35.

37. Kikano GE, Zyzanski SJ, Gotler RS, Stange KC. High-volume practice: are there trade-offs? Fam Pract Manage 2000;7:63-4.

38. Zyzanski SJ, Stange KC, Langa D, Flocke SA. Trade-offs in high-volume primary care practice. J Fam Pract 1998;46:397-402.

39. Knight T, Leech F, Jones A, et al. Sphygmomanom- eters in use in general practice: an overlooked aspect of quality in patient care. J Hum Hypertens 2001; 15:681-4.

40. Pedone C, Lapane KL. Generalizability of guidelines and physicians' adherence. Case study on the Sixth Joint National Commitee's guidelines on hypertension. BMC Public Health 2003;3:24.

41. Worrall G, Chaulk P, Freake D. The effects of clinical practice guidelines on patient outcomes in primary care: a systematic review. Can Med Assoc J 1997;156:1705-12.

42. Werner RM, Asch DA. The unintended consequences of publicly reporting quality information. JAMA 2005;293:1239-43.

43. Hofer TP, Hayward RA, Greenfield S, Wagner EH, Kaplan SH, Manning WG. The unreliability of individual physician "report cards" for assessing the costs and quality of care of a chronic disease. JAMA 1999;281:2098-105.

44. Werner RM, Asch DA, Polsky D. Racial profiling: the unintended consequences of coronary artery bypass graft report cards. Circulation 2005;111:125763. 